\title{
Secondary malignancy estimation in patients after mastectomy and adjuvant therapy
}

\author{
Oludare Folajimi Adeyemi', Okhuomaruyi David Osahon², Enosakhare Godwin Okungbowa ${ }^{3}$ \\ 'Radiotherapy and Clinical Oncology, University of Benin Teaching Hospital, Benin City 234, Nigeria. \\ ${ }^{2}$ Department of Physics, University of Benin, Benin City 234, Nigeria. \\ ${ }^{3}$ Department of Radiography and Radiation Science, University of Benin, Benin City 234, Nigeria.
}

Correspondence to: Dr. Enosakhare Godwin Okungbowa, Department of Radiography and Radiation Science, University of Benin, Benin City 234, Nigeria. E-mail: enosakhare.okungbowa@uniben.edu

How to cite this article: Adeyemi OF, Osahon OD, Okungbowa EG. Secondary malignancy estimation in patients after mastectomy and adjuvant therapy. J Cancer Metastasis Treat2018;4:53. http://dx.doi.org/10.20517/2394-4722.2018.12

Received: 23 Feb 2018 First Decision: 10 Apr 2018 Revised: 21 Jun 2018 Accepted: 11 Jul 2018 Published: 8 Oct 2018

Science Editor: Lucio Miele Copy Editor: Cui Yu Production Editor: Zhong-Yu Guo

\begin{abstract}
Aim: Secondary malignancy estimation after radiotherapy of post mastectomy patients is becoming an important subject for comparative treatment planning. The data from modern treatment planning systems provide accurate three-dimensional dose distributions for each individual patients, thereby opening up new possibilities for more precise estimates of secondary cancer incidence rates in the irradiated organs.
\end{abstract}

Methods: This study estimates the probability of secondary malignancy using radiobiological model for post mastectomy patients in a low-resource center, Nigeria. The secondary cancer complication probability (SCCP) was computed for linear, linear-exponent and linear-plateau models.

Results: The result shows that comparing the three models the mean SCCP for the contralateral breast ranged between $0.41 \%-0.93 \%$; for the lung (0.34\%-5.93\%); while for the chest wall is between $0.65 \%-31.95 \%$. Also, the result showed that based on the differential dose volume histogram, the SCCP in the chest wall is highest compared to the lung and contralateral breast; while the linear model overestimate the risk of secondary malignancy, the linear-exponent and the linear plateaus gave values not outrageously high.

Conclusion: The models in this study have shown that the risk of secondary malignancy in these post mastectomy patients is low.

Keywords: Probability, radiobiological model, complication, malignancy 


\section{INTRODUCTION}

The most common malignancy reported among women worldwide is breast cancer ${ }^{[1]}$. In Nigeria, majority of patients that are diagnosed with breast cancer each year are firstly treated with surgery followed by radiation therapy $^{[2]}$. Recent technological developments in both diagnosis and treatment of breast cancer as well as awareness campaign of this disease have led to early detection and better treatment management. Subsequently, the increase in the population of long-term survivors of breast cancer patients ${ }^{[3]}$.

The early breast cancer trialists' collaborative group meta-analysis has shown an overall survival benefit in favour of adjuvant radiotherapy (RT) after breast cancer surgery ${ }^{[4]}$. Although, the risk for radiotherapy treated patients regarding the induction of secondary cancer is small, it remains a relevant consideration among post mastectomy patients ${ }^{[5]}$. Quite a number of population-based studies have shown the association between primary breast tumour irradiation and the risk of second cancer within or outside the treatment field ${ }^{[6-8]}$.

In most cases, the treatment of breast cancers are with surgery, radiotherapy and chemotherapy, or most often with a blend of all the above. A significant proportion of patients diagnosed with breast cancer usually undergo radiotherapy ${ }^{[9]}$. Although, following radiotherapy, the cure often a times comes at a price of developing the risk of a second cancer among breast cancer survivors, it is however higher than that for the general population ${ }^{[6,8,10-12]}$.

In particular, irradiation of surrounding tissues during breast RT can cause secondary malignancies to develop within these tissues ${ }^{[13]}$. Secondary malignancy refers to a new histologically proven primary cancer in a person who has survived an earlier cancer event. While the benefits of RT outweigh the risks of developing subsequent cancers, it is imperative to evaluate the long-term consequences of breast cancer therapy. Modelling secondary cancer risk is not very new, and has been applied for many cancer diseases, also for breast cancer patients ${ }^{[14,15]}$, however developing countries with low resource RT centers are yet to adopt this approach. Applying this modelling approach, will go a long way to give quality assurance as to the nature of treatment plan patients are exposed to. The aim of this study is to estimate the risk of secondary cancer after radiotherapy of post mastectomy patients using radiobiological model.

\section{METHODS}

Forty-six patients treated in the Radiotherapy Unit, University of Benin Teaching Hospital, Benin city, Nigeria, between January 2012 and March 2014 for breast cancer after radical mastectomy were included in this study. All patients underwent computed tomography (CT) simulation in supine position on an angled board, with both arms placed above their head, which was rotated to the contralateral side (GE Brightspeed CT-scanner, GE Medical Systems). Patients received 50 Gy in 25 fractions for 5 weeks. The Elekta PrecisePlan was used for the computerised planning process. The organs at risk were the heart and lungs. The Elekta radiotherapy machine was used in treating the patients.

After the patients information have been annonymized the imported dose volume histograms (DVHs) from the computerised treatment planning system will now be used to calculate the equivalent uniform dose (EUD) and the secondary cancer complication probability (SCCP).

\section{EUD}

This is defined as the uniform dose that, if delivered over the same number of fractions as the non-uniform dose distribution of interest, yields the same radiobiological effect ${ }^{[16]}$.

The phenomenological formula for the generalised EUD (i.e., normal and tumor cells) as proposed by 
Table 1. Parameters used to calculate the secondary cancer complication probability

\begin{tabular}{llllc}
\hline Organs & $\alpha\left(\mathbf{G y}^{-1}\right)$ & $\delta\left(\mathbf{G y}^{-1}\right)$ & $\left.\mathbf{I n}_{\text {org }} \mathbf{~} \mathbf{0} / \mathbf{G y}\right)$ & Source \\
\hline Breast & 0.085 & 0.139 & $0.78[0.6-1.0]$ & {$[21]$} \\
Lungs & 0.085 & 0.150 & $1.68[1.1-2.3]$ & {$[22]$} \\
\hline
\end{tabular}

Niemierko $(1997)^{[17]}$ is

gEUD $=\left(\sum_{i}^{\text {口 }} v_{i} D_{i}^{a}\right)^{\frac{1}{a}}[18]$

Where $v_{\mathrm{i}}$ is fractional organ volume receiving a dose of $D_{\mathrm{i}}$ and a is tissue-specific parameter that describes the volume effect.

\section{SCCP}

The theory of SCCP adopted for this study is based on the Schneider model ${ }^{[19]}$ :

(1) $S C C P=\ln _{\text {org }} O E D_{\text {org }}$

where Inorg is the organ specific absolute cancer incidence rate for a low dose in percent per gray. These values represent lifetime risk, and assume a residual life expectancy of 50 years. Therefore, any effect of radiation-induced breast cancer associated with age was ignored in this study. Data from atomic bomb survivor was used to estimate the inorg for the breast and thereafter applied to whole-body irradiation. OEDorg is the organ equivalent dose and represents the corresponding dose in gray for an inhomogeneous dose distribution, which if it was distributed evenly throughout the organ, would cause similar radiationinduced cancer incidence ${ }^{[19]}$.

Three different dose-response models: linear, linear-exponential, and linear-plateau based on the differential DVHs was used in this study to compute the organ equivalent dose (OED $)^{[20]}$.

(2) $O E D_{\text {lin }}=\left(\frac{1}{V_{T}}\right) \sum_{i}^{\text {口 }}\left(v_{i} \cdot D_{i}\right)$

(3) $O E D_{\text {in-exp }}=\left(\frac{1}{V_{T}}\right) \sum_{i}\left(v_{i} \cdot D_{i} e^{-\alpha D_{i}}\right)$

(4) $O E D_{\text {lin }-p \text { lat }}=\left(\frac{1}{V_{T}}\right) \sum_{i}\left(v_{i} \cdot\left(\frac{1-e^{-\delta_{\text {org }} D_{i}}}{\delta_{\text {org }}}\right)\right)$

The parameters $\alpha$ and $\delta$ are the organ specific model parameters for their respective dose-response models. The parameters used to calculate SCCP is given in Table 1.

\section{Data analysis}

The study employed descriptive and inferential statistics to analyse the data. Descriptive statistics used are mean, standard error of mean, percentage frequency distribution; while inferential statistics used include correlation analysis and one way analysis of variance; Scheffe post hoc was used to separate means where significant difference is observed in the SCCP of the different groups of mean dose and EUD. The level of significance was set at 0.05 . The analysis was carried out using STATA version 12 .

\section{RESULTS}

Using SCCP to evaluate the plans for risk of secondary cancer complication in the contralateral and chest walls and the paired lungs, there was observed difference between the linear, linear-exponent and linearplateau dose risk models for SCCP due to the fact that the linear model deviates from the other two models for dose larger than 5 Gy. This was very noticeable in the organs exposed with higher doses (paired lungs and planning target volume). This is given in Table 2. 
Table 2. The secondary cancer complication probability (linear, linearexponent, plateau) indices for different organs

\begin{tabular}{lccc}
\hline Models & Contralateral breast (\%) & Lung (\%) & Chest wall (\%) \\
\hline Linear & $0.93 \pm 0.24$ & $5.93 \pm 0.54$ & $31.96 \pm 2.08$ \\
Linear exponent & $0.41 \pm 0.05$ & $0.34 \pm 0.03$ & $0.65 \pm 0.06$ \\
Plateau & $0.48 \pm 0.07$ & $1.81 \pm 0.12$ & $4.83 \pm 0.26$ \\
\hline
\end{tabular}

Table 3. Correlation of dose volume histogram parameters of breasts, chest walls and lungs with the secondary cancer complication probability

\begin{tabular}{|c|c|c|c|}
\hline & Linear & Linear-exponent & Linear-plateau \\
\hline \multicolumn{4}{|c|}{ Contralateral breast } \\
\hline Max dose & 0.437 & 0.179 & $0.546^{*}$ \\
\hline Min dose & 0.387 & 0.124 & $0.487^{*}$ \\
\hline Mean dose & 0.418 & 0.170 & $0.606^{* *}$ \\
\hline Volume & -0.113 & -0.293 & -0.139 \\
\hline EUD & - & - & - \\
\hline \multicolumn{4}{|l|}{ Lung } \\
\hline Max dose & 0.318 & 0.096 & 0.283 \\
\hline Min dose & $0.711^{\star \star}$ & 0.390 & $0.803^{* *}$ \\
\hline Mean dose & $0.912^{\star \star}$ & -0.125 & $0.870^{* *}$ \\
\hline Volume & -0.217 & -0.059 & -0.179 \\
\hline EUD & $0.759^{* \star}$ & -0.079 & $0.732^{\star \star}$ \\
\hline \multicolumn{4}{|l|}{ Chest wall } \\
\hline Max dose & 0.040 & 0.085 & 0.059 \\
\hline Min dose & $0.936^{\star \star}$ & 0.217 & $0.830^{* *}$ \\
\hline Mean dose & $0.989^{\star \star}$ & 0.361 & $0.870^{\star \star}$ \\
\hline Volume & -0.373 & $-0.869^{\star \star}$ & $-0.469^{\star}$ \\
\hline EUD & - & - & - \\
\hline
\end{tabular}

The relationship between DVH parameters and SCCP for the breasts, chest walls and lungs is presented in Table 3. It shows that the DVH parameters of the contralateral breasts did not show any significant relationship with the linear and linear-exponent models, while for the linear-plateau model a positive significant positive relationship exist between the max, min and mean doses. This shows that the max, min and mean doses on the DVH plan is predicative of secondary cancer. The DVH parameters of the lungs did not show any significant relationship with Linear-exponent SCCP; while the min, mean and EUD showed very strong positive relationship with the linear and linear-plateau SCCP. In the chest walls, the min and mean dose showed significant positive relationship with linear model SCCP, volume showed significant negative relationship with linear-exponent SCCP; while min and mean doses and volume showed significant positive and negative relationship respectively with linear-plateau model SCCP. It is interesting to note that in all the three organs, the minimum and mean doses are very strong positive parameters to be considered when planning a patient to reduce the risk of secondary cancer.

Table 4 shows the mean comparison of SCCP at different mean dose to the lung. From the table, it is evidence that for the linear model as the dose increases the SCCP value also increases significantly, but the linear-exponent model did not show any significance as increase dose did not affect the SCCP. The linearplateau model also showed significance in the mean comparison. The different treatment groups (mean dose) had significantly different SCCP and it follows an increasing order with mean dose.

Table 5 shows the mean comparison of SCCP at different EUD to the lung. From the table, it is clear that for the linear and linear-plateaus models showed significant differences on comparing the EUD groups; while the linear-exponent model did not show any significant difference $(P>0.05)$. 
Table 4. Mean comparison of the secondary cancer complication probability at different mean doses to the lung

\begin{tabular}{lcccc}
\hline & \multicolumn{1}{c}{$\mathbf{5}$ Gy } & $\mathbf{5 - 1 0}$ Gy & Above 10 Gy & $\boldsymbol{P}$ \\
\hline Linear & $3.01 \pm 0.91$ & $5.87 \pm 0.31$ & $9.78 \pm 0.60$ & 0.000 \\
Linear-exponent & $0.39 \pm 0.10$ & $0.32 \pm 0.02$ & $0.32 \pm 0.02$ & 0.558 \\
Linear-plateau & $1.13 \pm 0.28$ & $1.86 \pm 0.05$ & $2.49 \pm 0.12$ & 0.000 \\
\hline
\end{tabular}

Means with different superscripts are statistically significant at $P<0.05$

Table 5. Mean comparison of the secondary cancer complication probability at different equivalent uniform dose to the lung

\begin{tabular}{lcclc}
\hline & $<\mathbf{5 ~ G y}$ & $\mathbf{5 - 1 0}$ Gy & Above 10 Gy & $\boldsymbol{P}$ \\
\hline Linear & $4.13 \pm 1.00$ & $5.92 \pm 0.35$ & $10.16 \pm 0.65$ & 0.000 \\
Linear-exponent & $0.33 \pm 0.05$ & $0.35 \pm 0.04$ & $0.30 \pm 0.02$ & 0.851 \\
Linear-plateau & $1.45 \pm 0.24$ & $1.83 \pm 0.09$ & $2.59 \pm 0.11$ & 0.004 \\
\hline
\end{tabular}

Means with different superscripts are statistically significant at $P<0.05$

\section{DISCUSSION}

The risk of secondary malignancy in this study is $4.83 \%$ for the chest wall. This statistics is quite higher than the reported epidemiological result of Burt et al ${ }^{[23]}$ of approximately $3.4 \%$ of secondary malignancies were attributed to radiation therapy. This shows that to a great extent, radiobiological model agrees with epidemiological results; and can thus be incorporated into clinical evaluation of treatment plans during quality check by the medical physics. This statistics is lower than other studies where $6 \%-9 \%$ of the second cancers among irradiated breast cancer patients were estimated to be associated with radiotherapy ${ }^{[2,25]}$. This increase in the estimated risk could be as a result of initial treatment with chemotherapy ${ }^{[26-29]}$. This probability associated with the use of chemotherapy alone is lower than that of patients that underwent chemotherapy and radiotherapy ${ }^{[30]}$.

The finding from this study does not corroborate the findings of Corradini et al.$^{[31]}$ who reported a secondary cancer risk to the lungs as $0.65 \%$ and $2.49 \%$ using the linear exponent model at 50 years and 70 years respectively for free breathing technique; while $0.63 \%$ and $2.42 \%$ was reported for the plateau model at 50 years and 70 years respectively. These values are however lower than the reported values in this study, but may be smaller if the deep-inspiration breath-hold radiotherapy technique is employed. Although no study has ascertained any significant difference in the risk of secondary cancer to the lungs using this technique, they however reported higher values of secondary cancer risk as well as radiation induced lung cancer ${ }^{[32-36]}$. In a meta-analysis, including over 700,000 women treated for early breast cancer, it was demonstrated that radiation therapy is significantly associated with an excess risk of second cancers in organs with fairly close proximity to the former treatment fields ${ }^{[37]}$.

The average SCCP values for the lungs is $0.34 \% \pm 0.03 \%$ using the linear-exponential model. In a previous study, average SCCP values using the linear-exponential model gave a prediction of $5.3 \% \pm 0.1 \%$ for post mastectomy radiation therapy $(\mathrm{PMRT})^{[38]}$; which is higher that the computed value in this study. It is however close to the value of $5.93 \% \pm 0.54 \%$ obtained using the linear model. It is worthy of note here that the results from SCCP estimations are indicative of lifetime risk, with a mean residual lifetime of 50 years. It has been reported that smoking during radiation therapy or earlier caused an increase of the 15 years risk of developing a lung cancer after radiation therapy and breast conserving surgery by $4.7 \%$ and $6 \%$, respectively when it was compared to $0.26 \%$ among non-smokers ${ }^{[39]}$. Apart from the inherent increased risk in cancer survivors due to lifestyle, chemotherapy and radiation therapy are both known to further boost the risk of second solid cancers $^{[20]}$.

The risk of developing cancer on the contralateral breast cancer after radiotherapy appears to be common 
among women who are in their premenopausal age (younger than age 40 to 45 years) when exposed to radiation therapy, however higher risk is observed for PMRT patients ${ }^{[40]}$. The mean age of patients in this study is $57.8 \pm 8.7$ years ( $46-83$ years). The mean SCCP of the patients in this study using the linear exponential dose-risk model was $0.41 \% \pm 0.05 \%$. This value is lower than the average SCCP value of $1.0 \%$ for volumetric modulated arc therapy reported by Nichols et al. ${ }^{[38]}$ using the linear-exponential dose-response model. The result of this study is very important for younger patients (below 50 years) who are at greater risk for radiogenic second malignancies. Hernandez et al. ${ }^{[4]]}$ reported that no excess breast cancer risk has been found among women irradiated at age 40 years or older, while Boice et al. ${ }^{[42]}$ showed that after the age of 45 years radiation exposure with mean radiation dose of 2.51 Gy entails very little, if any at all or no risk (relative risk, 1.01) of radiation-induced breast cancer for a female population with an average age of 51.7 years.

As much as several studies have reported second cancers attributed to the treatment of the primary, were identified in several anatomical sites ${ }^{[40-42]}$, several others have not shown any appreciable risk in developing second primary cancer after breast radiotherapy, outside the treatment field ${ }^{[43,44]}$.

There was significant increase in the risk of secondary malignancy as dose to the different organs increases. This agrees with the finding of Deutch et al. ${ }^{[45]}$ who reported that higher dose of radiotherapy to lung in breast cancer patients was associated with increased incidence of subsequent radiation induced malignancies in both ipsilateral and contralateral lungs.

\section{DECLARATIONS}

\section{Acknowledgments}

The authors wish to acknowledge the entire staff: Radiographers, Medical Physicists and Oncologist in the Department of Radiotherapy and Clinical Oncology, University of Benin Teaching Hospital, Benin City, Nigeria. Also, special thanks to Gracinda Mondlane a PhD Student (Medical Radiation Physics) in the Department of Physics, Stockholm University for supplying materials on some constants that aided the computations in this study.

\section{Authors' contributions}

Saw and contoured the patients: Adeyemi OF

Literatures collection: Osahon OD

Designed the study and carried out the data analysis: Okungbowa EG

\section{Availability of data and materials}

Data will be made available on request through the corresponding author.

\section{Financial support and sponsorship}

None.

\section{Conflicts of interest}

All authors declared that there are no conflicts of interest.

\section{Ethical approval and consent to participate}

We declare that the article does not require a Statement of Ethics, since all the clinical material was anonymised. Absolutely no information concerning the patients, themselves, were used, so no consent were necessary. 


\section{Consent for publication}

The study didn't make use of patients directly but through secondary data collection method. The patients already gave their consent before they went through radiotherapy.

\section{Copyright}

(c) The Author(s) 2018.

\section{REFERENCES}

1. Assi HA, Khoury KE, Dbouk H, Khalil LE, Mouhieddine TH, El Saghir NS. Epidemiology and prognosis of breast cancer in young women. J Thorac Dis 2013; doi: 10.3978/j.issn.2072-1439.2013.05.24.

2. Olajide TO, Ugburo AO, Habeebu MO, Lawal AO, Afolayan MO, Mofikoya MO. Awareness and practice of breast screening and its impact on early detection and presentation among breast cancer patients attending a clinic in Lagos, Nigeria. Niger J Clin Pract 2014;17:802-7.

3. Darby SC, Ewertz M, McGale P, Bennet AM, Blom-Goldman U, Brønnum D, Correa C, Cutter D, Gagliardi G, Gigante B, Jensen MB, Nisbet A, Peto R, Rahimi K, Taylor C, Hall P. Risk of ischemic heart disease in women after radiotherapy for breast cancer. N Engl J Med 2013;368:987-98.

4. Clarke M, Collins R, Darby S, Davies C, Elphinstone P, Evans V, Godwin J, Gray R, Hicks C, James S, MacKinnon E, McGale P, McHugh T, Peto R, Taylor C, Wang Y; Early Breast Cancer Trialists' Collaborative Group (EBCTCG). Effects of radiotherapy and of differences in the extent of surgery for early breast cancer on local recurrence and 15-year survival: an overview of the randomised trials. Lancet 2005;366:2087-106.

5. Fowble B, Hanlon A, Freedman G, Nicolaou N, Anderson P. Second cancers after conservative surgery and radiation for stages I-II breast cancer: identifying a subset of women at increased risk. Int J Radiat Oncol Biol Phys 2001;51:679-90.

6. Raymond JS, Hogue CJ. Multiple primary tumours in women following breast cancer, 1973-2000. Br J Cancer 2006;94:1745-50.

7. Mellemkjaer L, Friis S, Olsen JH, Scélo G, Hemminki K, Tracey E, Andersen A, Brewster DH, Pukkala E, McBride ML, Kliewer EV, Tonita JM, Kee-Seng C, Pompe-Kirn V, Martos C, Jonasson JG, Boffetta P, Brennan P. Risk of second cancer among women with breast cancer. Int J Cancer 2006;118:2285-92.

8. Brown LM, Chen BE, Pfeiffer RM, Schairer C, Hall P, Storm H, Pukkala E, Langmark F, Kaijser M, Andersson M, Joensuu H, Fosså SD, Travis LB. Risk of second non-hematological malignancies among 376,825 breast cancer survivors. Breast Cancer Res tr 2007;106:439-51.

9. Tubiana M. Can we reduce the incidence of second primary malignancies occurring after radiotherapy? A critical review. Radiother Oncol 2009;91:4-15.

10. Rubino C, de Vathaire F, Diallo I, Shamsaldin A, Lê MG. Increased risk of second cancers following breast cancer: role of the initial treatment. Breast Cancer Res Treat 2000;61:183-95.

11. Rubino C, de Vathaire F, Shamsaldin A, Labbe M, Lê MG. Radiation dose, chemotherapy, hormonal treatment and risk of second cancer after breast cancer treatment. Br J Cancer 2003;89:840-6.

12. Zhang W, Becciolini A, Biggeri A, Pacini P, Muirhead CR. Second malignancies in breast cancer patients following radiotherapy: a study in Florence, Italy. Breast Cancer Res 2011;13:R38.

13. Zhang W, Becciolini A, Biggeri A, Pacini P, Muirhead CR. Region of treatment in radiotherapy and second malignancies in breast cancer patients. J Cancer Therapy 2012;3:768-76.

14. Donovan EM, James H, Bonora M, Yarnold JR, Evans PM. Second cancer incidence risk estimates using BEIR VII models for standard and complex external beam radiotherapy for early breast cancer. Med Phys 2012;39:5814-24.

15. Johansen S, Danielsen T, Olsen DR. Estimated risk for secondary cancer in the contra-lateral breast following radiation therapy of breast cancer. Acta Oncol 2008;47:391-6.

16. Niemierko, A. (1999) A Generalized Concept of Equivalent Uniform Dose (EUD). Available from: http://www.scirp.org/ (S(lz5mqp453edsnp55rrgjct55))/reference/ReferencesPapers.aspx?ReferenceID=1679390. [Last accessed on 30 Sep 2018]

17. Niemierko A. Reporting and analyzing dose distributions: a concept of equivalent uniform dose. Med phys 1997;24:103-10.

18. Webb S, Nahum AE. A model for calculating tumour control probability in radiotherapy including the effects of inhomogeneous distributions of dose and clonogenic cell density. Phys Med Biol 1993;38:653-66.

19. Schneider U, Zwahlen D, Ross D, Kaser-Hotz B. Estimation of radiation-induced cancer from three-dimensional dose distributions: concept of organ equivalent dose. Int J Radiat Oncol Biol Phys 2005;61:1510-5.

20. Abo-Madyan Y, Aziz MH, Aly MM, Schneider F, Sperk E, Clausen S, Giordano FA, Herskind C, Steil V, Wenz F, Glatting G. Second cancer risk after 3D-CRT, IMRT and VMAT for breast cancer. Radiother Oncol 2014;110:471-6.

21. Schneider U1, Kaser-Hotz B. A simple dose-response relationship for modeling secondary cancer incidence after radiotherapy. Z Med Phys 2005; 15:31-7.

22. Schneider U, Kaser-Hotz B. Radiation risk estimates after radiotherapy: application of the organ equivalent dose concept to plateau doseresponse relationships. Radiat Environ Biophys 2005;44:235-9.

23. Burt LM, Ying J, Poppe MM, Suneja G, Gaffney DK. Risk of secondary malignancies after radiation therapy for breast cancer: comprehensive results. Breast 2017;35:122-9.

24. Berrington de Gonzalez A, Curtis RE, Gilbert E, Berg CD, Smith SA, Stovall M, Ron E. Second solid cancers after radiotherapy for breast cancer in SEER cancer registries. Br J Cancer 2010;102:220-6.

25. Maddams J, Parkin DM, Darby SC. The cancer burden in the United Kingdom in 2007 due to radiotherapy. Int J Cancer 2011;129:2885-93.

26. Morton LM, Gilbert ES, Hall P, Andersson M, Joensuu H, Vaalavirta L, Dores GM, Stovall M, Holowaty EJ, Lynch CF, Curtis RE, Smith 
SA, Kleinerman RA, Kaijser M, Storm HH, Pukkala E, Weathers RE, Linet MS, Rajaraman P, Fraumeni JF Jr, Brown LM, van Leeuwen FE, Fossa SD, Johannesen TB, Langmark F, Lamart S, Travis LB, Aleman BM. Risk of treatment-related esophageal cancer among breast cancer survivors. Ann Oncol 2012;23:3081-91.

27. Emadi A, Jones RJ, Brodsky RA. Cyclophosphamide and cancer: golden anniversary. Nat Rev Clin Oncol 2009;6:638-47.

28. Travis LB, Gospodarowicz M, Curtis RE, Clarke EA, Andersson M, Glimelius B, Joensuu T, Lynch CF, van Leeuwen FE, Holowaty E, Storm H, Glimelius I, Pukkala E, Stovall M, Fraumeni JF Jr, Boice JD Jr, Gilbert E. Lung cancer following chemotherapy and radiotherapy for Hodgkin's disease. J Natl Cancer Inst 2002;94:182-92.

29. Valagussa P, Moliterni A, Terenziani M, Zambetti M, Bonadonna G. Second malignancies following CMF-based adjuvant chemotherapy in resectable breast cancer. Ann Oncol 1994;5:803-8.

30. Swerdlow AJ, Higgins CD, Smith P, Cunningham D, Hancock BW, Horwich A, Hoskin PJ, Lister TA, Radford JA, Rohatiner AZ, Linch DC. Second cancer risk after chemotherapy for Hodgkin's lymphoma: a collaborative British cohort study. J Clin Oncol 2011;29:4096-104.

31. Corradini S, Ballhausen H, Weingandt H, Freislederer P, Schönecker S, Niyazi M, Simonetto C, Eidemüller M, Ganswindt U, Belka C. Leftsided breast cancer and risks of secondary lung cancer and ischemic heart disease: effects of modern radiotherapy techniques. Strahlenther Onkol 2018;194:196-205.

32. Darby SC, McGale P, Taylor CW, Peto R. Long-term mortality from heart disease and lung cancer after radiotherapy for early breast cancer: prospective cohort study of about 300,000 women in US SEER cancer registries. Lancet Oncol 2005;6:557-65.

33. Kirova YM, De Rycke Y, Gambotti L, Pierga JY, Asselain B, Fourquet A; Institut Curie Breast Cancer Study Group. Second malignancies after breast cancer: the impact of different treatment modalities. Br J Cancer 2008;98:870-4.

34. Prochazka M, Granath F, Ekbom A, Shields PG, Hall P. Lung cancer risks in women with previous breast cancer. Eur J Cancer 2002;38:1520-5.

35. Neugut AI, Murray T, Santos J, Amols H, Hayes MK, Flannery JT, Robinson E. Increased risk of lung cancer after breast cancer radiation therapy in cigarette smokers. Cancer 1994;73:1615-20.

36. Inskip PD, Stovall M, Flannery JT. Lung cancer risk and radiation dose among women treated for breast cancer. J Natl Cancer Inst 1994;86:983-8.

37. Grantzau T, Overgaard J. Risk of second non-breast cancer after radiotherapy for breast cancer: a systematic review and meta-analysis of 762,468 patients. Radiother Oncol 2015;114:56-65.

38. Nichols GP, Fontenot JD, Gibbons JP, Sanders ME. Evaluation of volumetric modulated arc therapy for postmastectomy treatment. Radiat Oncol 2014;9:66.

39. Obedian E, Fischer DB, Haffty BG. Second malignancies after treatment of early-stage breast cancer: lumpectomy and radiation therapy versus mastectomy. J Clin Oncol 2000;18:2406-12.

40. Travis LB, Ng AK, Allan JM, Pui CH, Kennedy AR, Xu XG, Purdy JA, Applegate K, Yahalom J, Constine LS, Gilbert ES, Boice JD Jr. Second malignant neoplasms and cardiovascular disease following radiotherapy. J Natl Cancer Inst 2012;104:357-70.

41. Hernandez M, Zhang R, Sanders M, Newhauser W. A treatment planning comparison of volumetric modulated arc therapy and proton therapy for a sample of breast cancer patients treated with post-mastectomy radiotherapy. J Proton Ther 2015; doi: 10.14319/jpt.11.9.

42. Boice JD Jr, Harvey EB, Blettner M, Stovall M, Flannery JT. Cancer in the contralateral breast after radiotherapy for breast cancer. N Engl J Med 1992;326:781-5.

43. Evans HS, Lewis CM, Robinson D, Bell CM, Møller H, Hodgson SV. Incidence of multiple primary cancers in a cohort of women diagnosed with breast cancer in southeast England. Br J Cancer 2001;84:435-40.

44. Levi F, Te VC, Randimbison L, La Vecchia C. Cancer risk in women with previous breast cancer. Ann Oncol 2003;14:71-3.

45. Deutsch M, Land SR, Begovic M, Wieand HS, Wolmark N, Fisher B. The incidence of lung carcinoma after surgery for breast carcinoma with and without postoperative radiotherapy. Results of national surgical adjuvant breast and bowel project (NSABP) clinical trials B-04 and B-06. Cancer 2003;98:1362-8. 